Original article

\title{
SEASONAL DIFFERENCES IN FATTY ACID CONTENT OF WHITE BRINE CHEESE OFFERED AT THE BULGARIAN MARKET
}

\author{
G. KALINOVA ${ }^{1}$, ZH. DIMITROV ${ }^{2}$, H. DASKALOV ${ }^{1}$, D. MLADENOVA ${ }^{1}$ \\ \& P. MECHKAROVA ${ }^{1}$
}

${ }^{1}$ National Diagnostic and Research Veterinary Institute, Sofia, Bulgaria;

${ }^{2}$ LB Bulgaricum Ltd, Sofia, Bulgaria

\section{Summary}

Kalinova, G., Zh. Dimitrov, H. Daskalov, D. Mladenova \& P. Mechkarova, 2018. Seasonal differences in fatty acid content of white brine cheese offered at the Bulgarian market. Bulg. J. Vet. Med., 22, No 1, 105-113.

\begin{abstract}
The present study provides scientific information for fatty acid composition of white brine cheese from cow milk, produced from all regions of Bulgaria, across seasons for the period 2012-2016. A total of 670 samples produced from different manufacturers and collected from supermarkets by Official control of Bulgarian Food Safety Agency (BFSA) were examined. Fatty acid composition was determined by gas chromatography. The milk fat purity of 18 samples was established through gas chromatographic analysis of triglycerides. Seasonal variations were observed in fatty acid composition of white brine cheese. The seasonal changes in the concentration of lauric, myristic, palmitic, stearic, oleic and $\alpha$-linolenic acids have largely contributed to the variation of fatty acid composition of cheese. Saturated fatty acids (SFAs) were in the range $68.39-71.53 \%$ of total FAs and the proportion of unsaturated fatty acids (UFA) was $28.44-31.61 \%$ of total FAs. Fourty-five out of examined samples have exhibited different fatty acid profile than that established in the present study for cow milk cheese. The determined SFAs were $44.7-57.5 \%$ and UFA varied from $42.5 \%$ to $55.3 \%$. The fatty acids with short chain $(\mathrm{C} 4: 0 \div \mathrm{C} 10: 0)$ were not detected or in traces, lauric and myristic acids were in small amounts, while palmitic and oleic acids predominated in the fatty acid composition of cheese analogues.
\end{abstract}

Key words: fatty acid composition, white brine cheese

\section{INTRODUCTION}

The white brine cheese is the most popular cheese consumed in Bulgaria. The cheese is a rich source of essential nutrients: proteins, amino acids, fat, fatty acids, vitamins and minerals. Despite of its high nutritional value, the consumers are increasingly aware that fat and specific fatty acids can affect human health.

The content of fatty acids in cheese depends on the fatty acid concentration in 
the unprocessed raw milk. Bovine milk fat contains a large number of fatty acids (Taylor \& MacGibbon, 2011). Saturated fatty acids (SFAs) are $62 \%$ to $70 \%$ of total fatty acids with the most important from a quantitative viewpoint: palmitic (C16:0), lauric (C 12:0) and myristic (C14:0) fatty acids. Unsaturated fatty acids (UFAs) are $30 \%$ to $35 \%$ of total fatty acids with oleic acid $(\mathrm{C} 18: 1,9 \mathrm{c})$ being the main monounsaturated fatty acid.

A detailed report on fatty acid composition of the Dutch bovine milk composition in 2005 showed seasonal variations (Heck et al., 2009). SFAs ranged from 73 to $74 \%$ of total fatty acids (FAs) in winter milk and to $68-69 \%$ in summer samples. The variations were attributed to the differences in the diets of the cows between the two seasons.

Significant differences between the indoor and the grazing period were found in the concentration of 16 fatty acids in the milk from three mountain dairy farms in the Czech Republic (Frelich et al., 2009).

The fatty acid content of Greek feta and hard cheeses was reported by Zlatanos et al. (2002). The determined SFAs were $68.9 \%$ to $74.1 \%$ of total FAs and UFAs were $22.3 \%-26.9 \%$ of total FAs. Ten types of traditional Turkish cheeses were studied for fatty acid composition (Donmez et al., 2005). The content of SFAs ranged from 60.8 to $76.6 \%$ of total FAs, UFAs share was $22.9-38.7 \%$.

Cheese analogues were developed in the United States in the early 1970s and the main aim has been to create cheaper cheese substitutes for the industrial and catering cheese sectors, where they have numerous applications: frozen pizza toppings, slices in beef burgers, and as an ingredient in salads, sandwiches, cheese sauces, cheese dips, and ready-prepared meals. In Europe, cheese analogues are used increasingly in the industrial sector as ingredients in formulated foods such as processed meat products and combined 'cheese' products: savory snack toppings, and pasta meals, other applications as spaghetti sprinkling, as an ingredient of grated cheese blends (Guinee, 2011).

Recently, cheese analogues, produced in some Bulgarian dairy plants were offered at the market with label "white brine cheese". Probably, due to economic reasons and the shortage of raw milk in Bulgaria, the producers replace milk fat with cheaper non-milk fats. The sales of cheese analogues without informing the consumer are a serious concern related to a breach of the current legislation, as well as consumer delusion about the composition of the product.

In order to achieve a high level of health protection for consumers and to guarantee their right of information, Regulation (EU) 1169/2011 has required by December 2016 the presence of a mandatory nutrition declaration on the label of the product. The amount of saturated fatty acids, and information on the amounts of monounsaturated and polyunsaturated fatty acids are important elements of the nutrition declaration.

Few studies on fatty acid composition of white brine cheese offered at the Bulgarian market were performed, with limited number of examined samples. Naydenova et al. (2013) studied fatty acid composition of 39 marketed white brine cheeses and imitation products from March 2009 to November 2011 and found large differences between fatty acid content of 13 imitation products (cheese analogues) and samples white brine cheese. The concentrations of short chain fatty acids (C4:0-C10:0) of cheese analogues were $<0.5 \%$ of total FAs, while palmitic acid $-44.2 \%$ of total FAs. 
Taking into account the importance of the problem and the lack of systematic scientific information on the subject, we aimed to study fatty acid composition of white brine cheese offered at the Bulgarian market and to determine seasonal variations in its content.

\section{MATERIALS AND METHODS}

A high number of white brine cheese from cow milk samples (670), produced by different manufacturers from all regions of Bulgaria were analysed as followed: 385 samples (May - October), referred to as summer samples and 285 samples (November - April) termed winter samples. The samples were collected during 20122016 from supermarkets and brought to the laboratory by the Official control of Bulgarian Food Safety Agency (BFSA).

Fatty acid composition of white brine cheese was determined by gas chromatographic method described in ISO 15885:2002. The fat extraction (Soxhlet extraction) was carried out in accordance with ISO 14156. Methyl esters of the extracted fat were prepared by trans esterification method BSS EN ISO 12966 3/2010. Gas chromatographic analyses were performed using a gas chromatograph Agilent Technologies 6890 N, FID, capillary column: Supelco $\mathrm{SP}^{\mathrm{TM}}-2560$ Fused Silica: $100.0 \mathrm{~m} \times 0.25 \mathrm{~mm} \times 0.2$ $\mu \mathrm{m}$ film thickness. Chromatographic conditions: inlet temperature $-250{ }^{\circ} \mathrm{C}$, split mode $1: 100$, carrier gas - nitrogen, temperature regime: $60{ }^{\circ} \mathrm{C} / 240{ }^{\circ} \mathrm{C}$. Identification and quantification of fatty acids were performed by CRM 47885, Supelco 37 Component FAME Mix (Traceable Certified Reference Materials), purchased from Supelco SIGMA - ALDRICH.

The milk purity of 18 samples was determined by gas chromatographic analysis of triglycerides (reference method (BSS EN ISO 17678:2010). Fat extraction was done as per ISO 14156. Extracted milk fat was analysed by gas chromatography using capillary column to determine triglycerides, separated by total carbon numbers. $S$-values were calculated by inserting the mass fraction into suitable triglycerides equations. If the $S$-values exceeded the limits established with pure milk fat, the presence of foreign fat was detected.

The analyses were performed on gas chromatograph Shimadzu 17A; Inlet $\mathrm{T}^{\circ}=$ $350{ }^{\circ} \mathrm{C}$, column TG1 (Thermo, USA) - 10 $\mathrm{m}$; FID $\left(\mathrm{T}^{\circ}=370^{\circ} \mathrm{C}\right)$; temperature regime: $210{ }^{\circ} \mathrm{C} / 350{ }^{\circ} \mathrm{C}$. CRM 519 (produced by EC - IRMM) was used for identification and quantification of triglycerides.

Statistical analysis of the results was performed by ANOVA (Microsoft Excel 2010). Differences at $\mathrm{P}<0.05$ were considered statistically significant. The results are presented as $\%$ of total fatty acids (FAs) (mean value \pm standard deviation).

\section{RESULTS}

The data for fatty acid composition of white brine cheese from cow milk, offered at the Bulgarian market, are summarised in Table 1. The table included all fatty acids, whose amount was more than $1 \%$ of total FAs. The results were divided in two seasonal groups: cheese produced in winter (November - April) and cheese produced in summer (May - October).

The chromatogram of fatty acid profile of white cheese is presented on Fig. 1.

White brine cheese was rich in SFAs, with predominance of palmitic acid, especially in the winter samples (about $31 \%$ of total FAs). The other SFAs with higher amounts in winter samples than in summer ones were lauric and myristic acids. The short-chain fatty acids $(\mathrm{C} 4: 0 \div \mathrm{C} 10: 0)$ 
Seasonal differences in fatty acid content of white brine cheese offered at the Bulgarian market

Table 1. Fatty acid composition ( $\%$ of total fatty acids) of Bulgarian white brine cheese (mean \pm SD)

\begin{tabular}{|c|c|c|c|c|}
\hline Fatty acid & $\begin{array}{c}\text { Cheese } \\
(2012-2016) \\
(n=625)\end{array}$ & $\begin{array}{l}\text { Cheese produced } \\
\text { in winter, } \\
(\mathrm{n}=264)\end{array}$ & $\begin{array}{l}\text { Cheese produced } \\
\text { in summer, } \\
(n=361)\end{array}$ & $P$ value $^{1}$ \\
\hline Butyric acid, C4:0 & $4.65 \pm 0.52$ & $4.79 \pm 0.61$ & $4.45 \pm 0.26$ & 0.0008 \\
\hline Caproic acid, C6:0 & $2.60 \pm 0.27$ & $2.71 \pm 0.25$ & $2.43 \pm 0.20$ & $<0.0001$ \\
\hline Caprylic acid, C8:0 & $1.42 \pm 0.22$ & $1.49 \pm 0.18$ & $1.31 \pm 0.19$ & $<0.0001$ \\
\hline Capric acid, C10:0 & $3.03 \pm 0.40$ & $3.17 \pm 0.34$ & $2.82 \pm 0.39$ & $<0.0001$ \\
\hline Lauric acid, C12:0 & $3.20 \pm 0.48$ & $3.45 \pm 0.39$ & $2.84 \pm 0.33$ & $<0.0001$ \\
\hline Myristic acid, C14:0 & $10.60 \pm 0.82$ & $11.00 \pm 0.68$ & $10.02 \pm 0.60$ & $<0.0001$ \\
\hline $\begin{array}{l}\text { Pentadecanoic acid, } \\
\text { C15:0 }\end{array}$ & $1.47 \pm 0.34$ & $1.45 \pm 0.34$ & $1.49 \pm 0.33$ & NS \\
\hline Palmitic acid, C16:0 & $29.60 \pm 2.59$ & $30.97 \pm 2.28$ & $27.61 \pm 1.46$ & $<0.0001$ \\
\hline Palmitoleic acid, C16:1 & $1.44 \pm 0.23$ & $1.48 \pm 0.26$ & $1.36 \pm 0.14$ & NS \\
\hline Stearic acid, C18:0 & $12.03 \pm 1.92$ & $10.94 \pm 1.41$ & $13.61 \pm 1.40$ & $<0.0001$ \\
\hline Oleic acid, $\mathrm{C} 18: 1,9 \mathrm{c}$ & $23.82 \pm 2.58$ & $22.30 \pm 2.11$ & $26.03 \pm 1.28$ & $<0.0001$ \\
\hline $\begin{array}{l}\text { Elaidic acid, C18:1, } 9 \\
\text { trans }\end{array}$ & $0.30 \pm 0.01$ & $0.30 \pm 0.01$ & $0.31 \pm 0.01$ & NS \\
\hline $\begin{array}{l}\text { Linolelaidic acid, } \\
\text { C18:2, } 9 \text { trans, } 12 \text { trans }\end{array}$ & $0.20 \pm 0.01$ & $0.20 \pm 0.01$ & $0.20 \pm 0.01$ & NS \\
\hline $\begin{array}{l}\text { Linoleic acid, } \\
\text { C18:2,9c,12c }\end{array}$ & $2.12 \pm 0.40$ & $2.09 \pm 0.46$ & $2.15 \pm 0.31$ & NS \\
\hline Linolenic acid, $\alpha-C 18: 3$ & $0.53 \pm 0.17$ & $0.49 \pm 0.14$ & $0.65 \pm 0.18$ & 0.003 \\
\hline $\begin{array}{l}\text { Total saturated fatty } \\
\text { acids, } \Sigma \text { SFA }\end{array}$ & $70.26 \pm 2.24$ & $71.53 \pm 1.79$ & $68.39 \pm 1.33$ & $<0.0001$ \\
\hline $\begin{array}{l}\text { Total unsaturated fatty } \\
\text { acids, } \Sigma \text { UFA }\end{array}$ & $29.74 \pm 2.24$ & $28.44 \pm 1.78$ & $31.61 \pm 1.32$ & $<0.0001$ \\
\hline
\end{tabular}

NS: non-significant.

were from $11.0 \%$ of total FAs in summer samples to $12.2 \%$ of total FAs in winter.

Stearic acid was the only SFA, whose proportion has increased from $10.94 \pm$ $1.41 \%$ in the winter to $13.61 \pm 1.40 \%$ in the summer and played a significant role in seasonal differences of fatty acid composition of white brine cheese. The other fatty acid, which was more abundant in samples, produced in summer, was the oleic acid $(\mathrm{C} 18: 1,9 \mathrm{c})$. It was the major monounsaturated fatty acid (MUFA) with concentration from $22.30 \pm 2.11 \%$ in winter to $26.03 \pm 1.28 \%$ in summer. The principal polyunsaturated fatty acids (PUFA) were the linoleic $(\mathrm{C} 18: 2,9 \mathrm{c}, 12 \mathrm{c})$ and $\alpha$ linolenic $(\mathrm{C} 18: 3,9 \mathrm{c}, 12 \mathrm{c}, 15 \mathrm{c})$ acids - both were $2.70 \%$. The linoleic acid was the predominant PUFA with $2.13 \%$ of total FAs. The content of linoleic acid was higher during the summer months, without statistical differences while the $\alpha$-linolenic acid raised its proportion in summer samples by $32 \%$, compared with winter ones $(\mathrm{P}<0.05)$.

Trans fatty acids (TFAs) were represented by the elaidic and linolelaidic acids. Relatively small amounts of them were found in studied cheese.

The observed seasonal variations in the fatty acid composition of cheese fat were compared with the average level during 2012-2016. C4:0 to $\mathrm{C} 10: 0$ were decreased by $4.3 \%-7 \%$; C12:0, C14:0, 


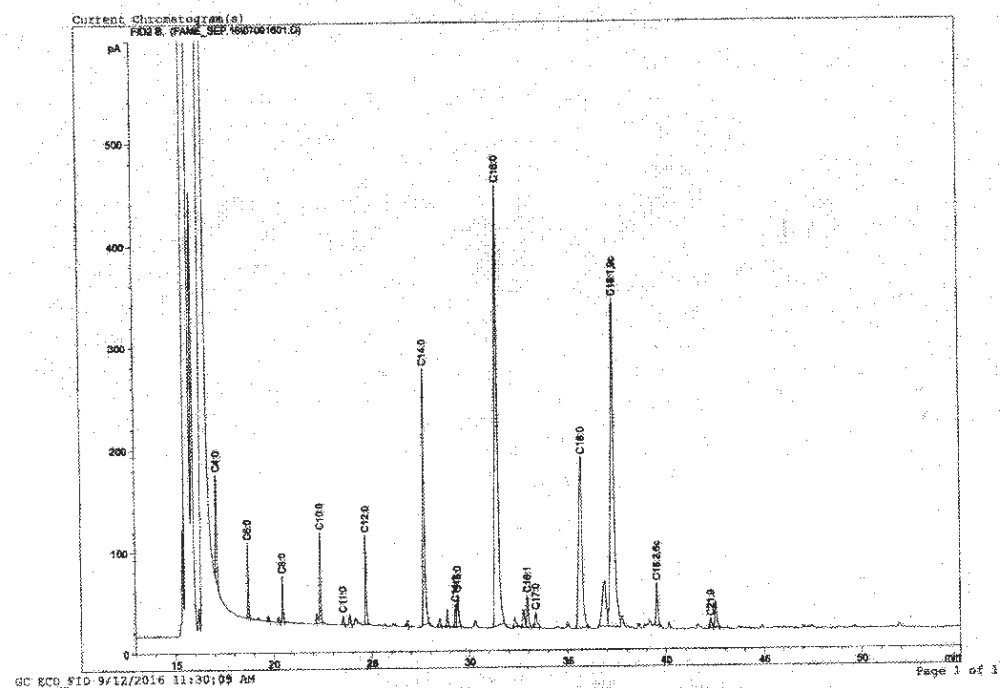

Fig. 1. Chromatogram of fatty acid composition of Bulgarian white brine cheese from cow milk.

$\mathrm{C} 16: 0$ and $\mathrm{C} 16: 1$ were reduced by $6-11 \%$ and $\mathrm{C} 18: 0, \mathrm{C} 18: 1,9 \mathrm{c}$ and $\alpha-\mathrm{C} 18: 3$ were increased by $9-23 \%$; $\Sigma$ SFAs were decreased by $3 \%$; $\Sigma$ UFAs were higher by $6.3 \%$ during summer. $\mathrm{C} 4: 0$ to $\mathrm{C} 10: 0$ were higher by $3-4.6 \%$; C12:0, C14:0, C16:0 and $\mathrm{C} 16: 1$ were increased by $3-5 \%$ and C18:0, C18:1 and $\alpha$-C18:3 were decreased by $6-9 \% ; \Sigma$ SFAs were increased by $2 \%$; $\Sigma$ UFAs were reduced by $4.4 \%$ during winter.

The seasonal changes of lauric, myristic, palmitic, stearic, oleic and $\alpha$-linolenic acids (C12:0, C14:0, C16:0, C18:0, C18:1 and $\alpha-C 18: 3)$ have contributed most to the variation of fatty acid composition of cheese.

Forty-five of examined white brine cheese samples have exhibited different fatty acid profile than that established in the present study for cow milk cheese. These were cheese analogues, fully or partially substituted with non-milk fat.

To detect adulteration of 18 samples, labelled as cheese, both methods: reference method for the determination of milk fat purity using gas chromatographic analysis of triglycerides and gas chromatographic analysis of fatty acid composition of milk fat were performed. The results are presented in Table 2.

Eight samples with $96 \%$ to $100 \%$ foreign fat were determined. The short-chain fatty acids $(\mathrm{C} 4: 0 \div \mathrm{C} 10: 0)$ typical for milk fat were not detected. Lauric and myristic acids were found as traces. SFAs $(44.72 \%)$ contained mostly palmitic and stearic acids. Total UFAs were more than SFAs and the amount of oleic acid was almost equal to total SFAs. In this group of products, milk fat was fully substituted with non-milk fat and the quantity of UFAs was higher than SFAs. The chromatogram of sample with non milk fat is presented on Fig. 2.

The rest of samples contained $45 \%$ to $55 \%$ foreign fat. The milk fat specific short chain fatty acids $(\mathrm{C} 4: 0 \div \mathrm{C} 10: 0)$ were $4.40 \%$, e.g. 3 times less than their normal quantity in cow milk cheese. The concentrations of fatty acids with medium chain length (C12:0 and C14:0) were 
Seasonal differences in fatty acid content of white brine cheese offered at the Bulgarian market

Table 2. Fatty acid composition (ISO 15885:2002), compared with purity of milk fat (BSS ISO 17678:2010) of products labelled as cheese (mean \% of total fatty acids)

\begin{tabular}{lccc}
\hline Fatty acid & $\begin{array}{c}\text { Cheese } \\
(\mathrm{n}=625)\end{array}$ & $\begin{array}{c}\text { Cheese analogues with } \\
\text { 45 } 55 \text { non milk fat, } \\
(\mathrm{n}=10)\end{array}$ & $\begin{array}{c}\text { Cheese analogues with } \\
96-100 \% \text { non milk fat, } \\
(\mathrm{n}=8)\end{array}$ \\
\hline C4:0 & 4.65 & 1.7 & 0 \\
C6:0 & 2.60 & 0.91 & 0 \\
C8:0 & 1.42 & 0.61 & 0 \\
C10:0 & 3.03 & 1.17 & 0.15 \\
C12:0 & 3.20 & 2.05 & 0.35 \\
C14:0 & 10.60 & 5.00 & 1.33 \\
C16:0 & 29.60 & 35.75 & 32.38 \\
C18:0 & 12.03 & 8.97 & 9.99 \\
C18:1,9c & 23.82 & 33.56 & 44.06 \\
C18:2,9c,12c & 2.12 & 6.54 & 9.38 \\
$\alpha-C 18: 3,3$ & 0.53 & 0.25 & 0.35 \\
\hline$\Sigma$ SFA & 70.26 & 57.54 & 44.72 \\
\hline$\Sigma$ UFA & 29.74 & 42.46 & 55.29 \\
\hline
\end{tabular}

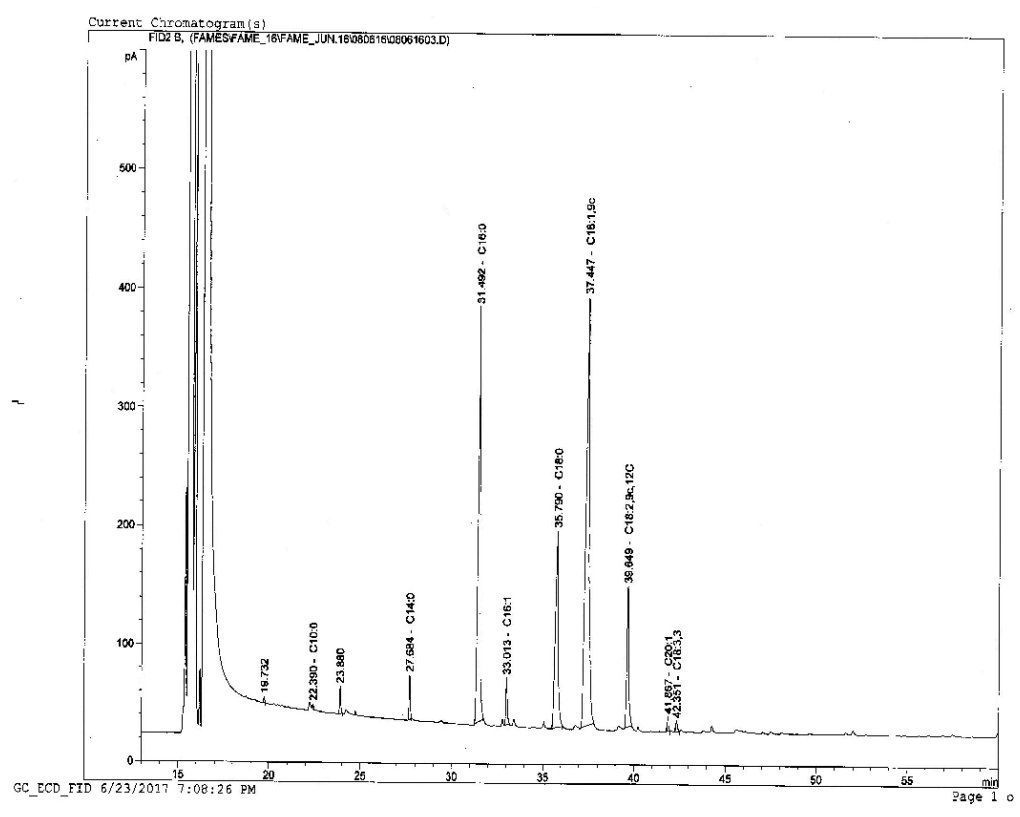

Fig. 2. Chromatogram of fatty acid composition of sample containing $96-100 \%$ non-milk fat.

around $7 \%$, which was twice less than normal amounts in white brine cheese. The palmitic and oleic acids were present in almost equal percentages (34-36\%).
The observed fatty acid profile characterised the products as partially replaced with non-milk fat. 


\section{DISCUSSION}

The results of studied white brine cheese were quite similar to our previous findings, where total SFAs varied in the range $67.92-72.69 \%$ and total UFA were $27.31-$ $32.08 \%$ (Kalinova, 2011). Ivanov et al. (2016) established comparable fatty acid composition of cow milk cheese, during its ripening $-69.2 \mathrm{~g} .100 \mathrm{~g}^{-1}$ fat for SFA and 30.8 g. $100 \mathrm{~g}^{-1}$ fat for UFA. Kinik et al. (2005) reported higher results for SFA $-73.90 \%$ in Turkish white pickled cheese, but on the basis of only 10 samples tested.

The seasonal changes in fatty acid composition of white brine cheese can be attributed to seasonal changes in milk used for its production. During the summer a high proportion of the feed of lactating cows is supplied through grazing, whereas in the winter, they are fed grain concentrates and conserved forages. Our recent study on fatty acid composition of Bulgarian cow's milk showed variations in the concentrations of SFAs (67.60 to $72.94 \%$ ) and UFAs (27.06 to $33.12 \%$ ), explained with seasonal feeding practices (Kalinova et al., 2017). Total SFAs of UK retail milk ranged from $67.2 \%$ of total FAs (March) to $71.7 \%$ of total FAs (December, January) (Kliem et al., 2013). The milk from Czech farms contained $67.2 \%$ SFAs during indoor period and $62.2 \%$ in summer months, during grazing (Frelich et al., 2009).

Despite observed differences in the quantities of $\mathrm{C} 4: 0-\mathrm{C} 10: 0(\mathrm{P}<0.05)$, shortchain FAs did not contribute much to the changes of total SFAs across the seasons. The concentration of short-chain FAs in Dutch and US milk were not affected significantly during the different seasons (Heck et al., 2009; O'Donnell-Megaro et al., 2011).

The higher levels of stearic and oleic acids (C18:0; $\mathrm{C} 18: 1,9 \mathrm{c})$ in white brine cheese during the summer months also corresponded with its content in milk. Both fatty acids approached $14.3 \%$ of total FAs for stearic and $26.2 \%$ of total FAs for oleic acid in summer samples of Bulgarian milk, due to increased intake of fresh forages. The grass used for grazing is rich of polyunsaturated fatty acids, such as C18:3 (Ferlay et al., 2006). The increased quantity of fresh grass increases $\mathrm{C}$ 18:3 concentration in summer diet of cows and respectively raises the concentrations of C18:0; C18:1, 9c; C18:1, 11t; C18:2, $9 \mathrm{c}, 12 \mathrm{c}$ and $\mathrm{C} 18 \mathrm{~s}, 3 \mathrm{c}, 12 \mathrm{c}, 15 \mathrm{c}$ in milk and decreases concentrations of shortchain FAs in milk (Chilliard et al., 2001). Our results for seasonal variations in fatty acid composition of Bulgarian white brine cheese were also in line with this explanation.

White brine cheese contained relatively low concentrations of trans fatty acids. Small concentrations of TFAs were found in Bulgarian milk also. These TFAs are naturally occurring, deriving from ruminant sources and should not be linked with TFAs from industrially hydrogenated vegetable oils, which raised the risk of cardiovascular diseases.

Comparative studies on fatty acid composition of white brine cheese presented close results to our findings for fatty acid profile of cheese analogues (Naydenova et al., 2010). The levels of short-chain fatty acids were significantly low $(0.67 \%$ to $10.3 \%)$, medium-chain fatty acids were $49 \%$ to $55 \%$ and longchain ones: $38-50 \%$.

The cheese analogues should be manufactured not only for economic reasons; the products should have nutritional equivalence of natural cheese. The producers must invest in the development of food products that can guarantee the health of consumers. The cheese analo- 
gues with substituted milk fat could be of interest for consumers of foods which contain less saturated fat, cholesterol, and calories, but they must be labelled according to the requirements of legislation. Such products are useful in controlling body weight and reducing the risk of heart and artery diseases (Mortensen \& McCarthy, 1991).

\section{CONCLUSIONS}

Seasonal variations were observed in fatty acid composition of white brine cheese from cow milk. The seasonal changes in the content of lauric, myristic, palmitic, stearic, oleic and $\alpha$-linolenic acids have contributed most to the variation of fatty acid composition of cheese.

Non-permitted full or partial replacement with non-milk fat was demosntrated in $7 \%$ of samples, labelled as white brine cheese. The cheese analogues with 58\% SFAs and $42 \%$ UFAs corresponded to product with $45 \%$ to $55 \%$ non milk fat, while the analogues with 96-100\% non milk fat contained $45 \%$ SFAs and $55 \%$ UFAs.

\section{REFERENCES}

Bulgarian State Standard BDS EN ISO 17678:2010. Milk and milk products - Determination of milk fat purity by gas chromatographic analysis of triglycerides (Reference method).

Bulgarian State Standard BDS EN ISO 12966 $-3 / 2010$. Animal and vegetable fats and oils - Gas chromatography of fatty acid methyl esters - Part 3: Preparation of methyl esters using trimethylsulfonium hydroxide (TMSH) (ISO 12966-3:2009).

Chilliard, Y., A. Ferlay \& M. Dorean, 2001. Effect of different types of forages, animal fat or marine oils in cow's diet on milk fat secretion and composition, especially con- jugated linoleic acid (CLA) and polyunsaturated fatty acids. Livestock Production Science, 70, 31-48.

Donmez, M., A. K. Seckin, O. Sagdic \& B. Simsek, 2005. Chemical characteristics, fatty acid compositions, conjugated linoleic acid contents and cholesterol levels of some traditional Turkish cheeses. International Journal of Food Sciences and Nutrition, 56, 157-163.

Ferlay, A., B. Martin, Ph. Pradel, J. L. Coulon \& Y. Chilliard, 2006. Influence of grassbased diets on milk fatty acid composition and milk lipolytic system in Tarentaise and Montbeliarde cow breeds. Journal of Dairy Science, 89, 4026-4041.

Frelich, J., M. Šlachta, O. Hanuš, J. Špička \& E. Samková, 2009. Fatty acid composition of cow milk fat produced on low-input mountain farms. Czech Journal of Animal Science, 54, 532-539.

Guinee, T. P., 2011. Cheese analogues In: Encyclopedia of Dairy Sciences, $2^{\text {nd }}$ edn, eds. J. W. Fuquay, P. F. Fox, P. L. H. McSweeney, Academic Press, imprint of Elsevier, London, vol. 1, pp. 814-821.

ISO 15885/IDF184:2002. Milk fat - Determination of fatty acid composition by gasliquid chromatography.

Heck, J. M. L., H. J. F. van Valenberg, J. Dijkstra \& A. C. M. van Hooijdonk, 2009. Seasonal variation in the Dutch bovine raw milk composition. Journal of Dairy Science, 92, 4745-4755.

Ivanov, G., T. Balabanova, M. Ivanova \& R. Vlaseva, 2016. Comparative study of Bulgarian white brined cheese from cow and buffalo milk. Bulgarian Journal of Agricultural Science, 22, 643-646.

Kalinova, G. , Ts. Tomanova, H. Chanev, S. Brachkova \& A. Slavova, 2011. Study of the fatty acid composition of cow's brine cheese for the presence of vegetable fat by gas chromatographic method. In: Proceedings of Jubilee Scientific Session „110 Years NDRVMT', Sofia, Bulgaria, pp. 205-209 (BG). 
Kalinova, G., M. Marinova., H. Daskalov, D. Mladenova \& P. Mechkarova, 2017. Fatty acid composition of Bulgarian milk. In: Proceedings of $3^{\text {rd }}$ International conference "The challenges for quality and safety along the food chain"(Abstract book), Sofia, Bulgaria, New Bulgarian University, Sofia, p. 8.

Kinik, O., O. Gursoy \& A. K. Seckin, 2005. Cholesterol content and fatty acid of most consumed Turkish hard and soft cheeses. Czech Journal of Food Science, 23, 166172.

Kliem, K. E., K. J. Shingfield, K. M. Livingstone \& D. Ian Givens, 2013. Seasonal variation in the fatty acid composition of milk available at retail in the United Kingdom and implications for dietary intake. Food Chemistry, 141, 274-281.

Mortensen, H. \& J.McCarthy, 1991. Imitation cheese products will gain importance. Scandinavian Dairy Information, 5, 1415 .

Naydenova N., K. Davidova, T. Iliev, G. Mihaylova, 2010. Comparative studies on the fatty acid composition of white brined cheese, marketed in the town of Zagora. Agricultural Science and Technology, 2, 105-110.

Naydenova, N., T. Iliev, G. Mihaylova \& S. Atanasova, 2013. Comparative studies on the gross composition of white brined cheese and its imitations, marketed in the town of Stara Zagora. Agricultural Science and Technology, 5, 221-229.
O'Donnell-Megaro, A., D. Barbano \& D. Bauman, 2011. Survey of the fatty acid composition of retail milk in the United States including regional and seasonal variations. Journal of Dairy Science, 94, 59-65.

Regulation (EU) 1169/2011 of The European Parliament and of The Council of $25 \mathrm{Oc}$ tober 2011 on the provision of food information to consumers.

Taylor, M. W. \& A. K. H. MacGibbon, 2011. Milk lipids. Fatty Acids. In: Encyclopedia of Dairy Sciences, $2^{\text {nd }}$ edn, eds. J. W. Fuquay, P. F. Fox, P. L. H. McSweeney, Academic Press, Elsevier, London, vol. 3, pp. 655-659.

Zlatanos, S., K. Laskaridis, C. Feist \& A. Sagredos, 2002. CLA content and fatty acid composition of Greek feta and hard cheeses. Food Chemistry, 78, 471-477.

Paper received 22.05.2017; accepted for publication 05.06.2017

\section{Correspondence:}

Ginka Kalinova

National Diagnostic and Research

Veterinary Institute,

15 Pencho Slaveykov Blvd,

1606 Sofia, Bulgaria,

e-mail: ginkakalinova@yahoo.com 